\title{
Ensino Híbrido: uma Investigação das Percepções dos Egressos do Pronatec Quanto à Utilização de Disciplinas Semipresenciais
}

\section{Hybrid Teaching: a PRONATEC Graduates Perception Investigation Regarding Semi Presential Subjects}

\author{
Adriano Rosa Alves ${ }^{\mathrm{a}}$;Eliza Adriana Sheuer Nantes*a; Daniel Ramos Nogueira;
}

\begin{abstract}
${ }^{a}$ Unopar, Programa de Pós-Graduação Stricto Sensu em Metodologias para o Ensino de Linguagens e suas Tecnologias. PR, Brasil.
bUniversidade Estadual de Londrina. Curso de Ciências Contábeis. PR, Brasil.
\end{abstract}

\begin{abstract}
Resumo
O presente artigo teve como objetivo analisar a percepção que os egressos obtiveram, durante seus estudos, sobre as disciplinas semipresenciais (ensino híbrido) ofertadas nos cursos do PRONATEC em uma instituição de ensino privado localizada na região norte do Estado do Paraná. Realizou-se uma pesquisa descritiva, bibliográfica, documental e quanti-qualitativa, como técnica específica para obter as informações requeridas, utilizou-se um questionário composto por 19 questões sobre aspectos relacionados à qualidade dos materiais disponibilizados, sendo as vídeoaulas, os fóruns, os conteúdos web e, também observado como fora desenvolvido a mediação dos tutores a distância. Nesta pesquisa, que obteve 60 respostas, foi possível associar, através do método estatístico qui-quadrado, quais as características e percepções assimiladas pelos egressos dos cursos do PRONATEC para realizarem ou não a indicação dos cursos ao seu rol de contatos sociais, avaliando os indicadores quem compuseram os materiais disponibilizados. Os dados amostrais que indicaram evidências estatísticas, nas quais os conceitos atribuídos pelos alunos que estavam associados à indicação ou não dos cursos do PRONATEC foram: webaula, vídeoaulas e a mediação dos tutores, todos estes menores que o valor de significância (valor-p 0,05). Por fim, ficou compreendido que o avanço tecnológico veio para auxiliar o homem na execução de suas atividades, mas, se ele não possuir a capacitação e competências necessárias para a utilização destas ferramentas, poderá sentir-se deslocado dos processos e métodos propostos, e isso é válido também para os métodos de aprendizagem e as ferramentas disponíveis aos discentes.
\end{abstract}

Palavras-chave: Disciplinas Semipresenciais. Ensino Profissionalizante. Ambiente Virtual de Aprendizagem. Competências Digitais.

\begin{abstract}
The carried study aimed analyzing PRONATEC project graduates from a Northern Paraná private institution and their perception about semi presential subjects (hybrid teaching). A descriptive, bibliographic, documental, quantitative and qualitative research was carried to obtain required information about the case; for that, a questionnaire containing 19 questions was taken by students. The content of the questions was related to video classes, forums, web classes and also, tutors mediation. Among the 60 answers, analyzed through the chi-square test, PRONATEC graduates'features and perceptions were understood, in order to commend or not the courses to their social contacts, evaluating indicators related to the provided materials throughout the course. Sample data indicated statistical evidence, showing the significant contents: web classes, video classes and tutors mediation as decisive aspects for students $(p \leq 0.05)$. Lastly, it can be concluded technological advancement helps one carrying out activities, still training and skills are considered as prerequisites for these tools' management. One may feel displaced from procedures and method, in this sense, it is also valuable for learning methods and tools available to students.
\end{abstract}

Keywords: Semi Presential Subjects. Vocational Education. Virtual Leaning Environment. Digital Skills.

\section{Introdução}

Partindo do pressuposto que a metodologia do ensino híbrido é formulada a partir da inserção do ensino online na estrutura curricular dos cursos presenciais e, de acordo com a Portaria MEC No 4059/2004 (BRASIL, 2004), a qual regulamenta e autoriza as instituições de ensino superior a ofertarem em seus currículos até $20 \%$ das disciplinas na modalidade $\mathrm{EaD}$, tendo sofrido uma alteração onde fora elevado para $40 \%$ a possibilidade de ofertar-se as disciplinas EaD, a partir da portaria MEC No 2.117/2019 (BRASIL, 2019), será observado qual o grau de percepção da qualidade das disciplinas semipresenciais ofertadas nos cursos do PRONATEC, de acordo com a percepção dos alunos egressos que realizaram algum curso ofertado pela instituição de ensino analisada.
Afirma Moran (2015) que a educação sempre adequou diferentes espaços, sujeitos, tempos, atividades e metodologias. Para o autor na educação, acontecem vários tipos de mistura, blended ou educação híbrida: de saberes e valores, quando integramos áreas de conhecimento e metodologias, com desafios, atividades, projetos, games, grupais ou individuais, colaborativos ou personalizados.

O modelo proposto pelo Clayton Christensen Institute, o ensino híbrido é um programa de educação formal, no qual o aluno aprende por meio do ensino online, com algum elemento de controle sobre tempo, lugar, o modo e/ou o ritmo de estudo, e por meio do ensino presencial, na escola (BACICH; TANZI NETO; TREVISANI, 2015).

De acordo com Horn e Staker (2015), o ensino híbrido surge como inovação sustentada em relação a sala de aula 
presencial (tradicional), com o intuito de possibilitar as vantagens e benefícios dos recursos online para a construção de uma aula interativa, que possibilite a flexibilidade de tempo e espaço de aprendizagem para os discentes, além de propiciar a utilização de hipertextos, ampliando a cabedal de informações pertinentes à um tema proposto para pesquisa e aprendizagem.

Segundo o Dicionário Crítico de Educação e Tecnologias e de Educação a Distância (2018, p.86), o Blended Learning (Ensino Híbrido) trate-se de um conceito de educação caracterizado pelo o uso de soluções combinadas ou mistas, com a interação entre modalidades presencial e a distância, entre abordagens pedagógicas e entre recursos tecnológicos. Dessa forma, a principal vantagem para o discente é de que as disciplinas semipresenciais, através da possibilidade de flexibilizar o tempo de estudos, favorece ao discente a viabilidade de conciliar suas atividades profissionais, pessoais e acadêmicas.

Para Bacich, Tanzi Neto e Trevisani (2015), o objetivo do ensino híbrido é possibilitar ao aluno aprender mais e melhor, por meio das mediações que as ferramentas tecnológicas podem oferecer, permitindo o desenvolvimento de novas habilidades cognitivas, além de preparar os alunos para as várias formas de sociabilidade e trocas de informação. Logo, esse modelo de aprendizado engloba uma série de aulas ou instruções presenciais que são acrescidas com a utilização da web ou do AVA para o acesso aos recursos de estudos (MOORE; KEARSLEY, 2013).

A relação com esta autonomia do aluno é apresentada pela noção de transferência do conhecimento, na qual, professor e aluno, mediante trocas de significados e do desenvolvimento de uma compreensão compartilhada, se transformam e modificam-se, com os alunos assumindo, progressivamente, a responsabilidade pelo seu próprio aprendizado (VYGOTSKY, 1991). Desse modo, é possível afirmar que a aprendizagem passa a dominar os discursos educacionais contemporâneos, pois "a ênfase das propostas pedagógicas e dos currículos escolares é na aprendizagem, e a centralidade do processo está no estudante" (OLIVEIRA, 2020, p. 9).

Utilizar-se do modelo híbrido pode propiciar um tempo significativo para os docentes desenvolverem as práticas pertinentes aos conteúdos teóricos a serem ministrados. Para Moran (2018), com a educação online, o papel do professor multiplica-se, exigindo evolução e adaptação diante das novas situações, processos e atividades.

Assim sendo, as instituições de ensino devem habilitar os sujeitos numa sociedade em que o alcance às informações e a tomada de decisões podem ser o diferencial para um sistema educativo de qualidade (BORGES; LOPES, 2019). Tal reflexão é suportada pelo desenvolvimento das tecnologias digitais que possibilitam a ampliação do espaço de diferentes naturezas que são interligadas e configuram a convivência dos sujeitos (BACKES; CHITOLINA; BARCHINSKI, 2017).
Isso procede em decorrência da educação estar interligada com a cultura cada vez mais pressionada pelas "práticas sociais típicas da cultura digital" personalizada a partir das redes sociais virtuais, devido a vastidão de informações disponibilizadas a partir de várias fontes (VALENTE; ALMEIDA; GERALDINI, 2017, p. 458). Outrossim, a cultura digital proporciona à aprendizagem compartilhada, por múltiplas possibilidades de encontros com pessoas próximas e distantes/conectadas, que se agrupam de forma mais aberta, ou organizada, pontual ou permanente, formal ou informal, espontânea ou estruturada, com ou sem supervisão, (MORAN, 2018).

Destarte, para que os discentes possam interagir com o ambiente virtual de aprendizagem (AVA), no qual a "rede social" torna-se um ambiente de estudos com a disponibilidade de materiais que compreendem conteúdos web repletos de hipertextos, com atividades virtuais, sugestões de leituras, acesso à biblioteca virtual e a oportunização de debates entre docentes, discentes e tutores, através dos fóruns que às disciplinas proporcionam para a reflexão do tema pesquisado e apresentado, se faz necessário que os participantes deste AVA possuam o letramento digital, para não elaborarem preconceitos e avaliações equivocadas quanto aos conteúdos disponibilizados.

De acordo com Caldeira e Brito (2019), o letrado digital deve ser capaz de comunicar-se em diferentes situações e ambientes, pois para a busca de informações na internet, o sujeito necessita saber analisar e avaliar a qualidade do conteúdo e sua veracidade, além de poder compreendê-las e, desta forma, aplicar os conhecimentos adquiridos em sua vida acadêmica, profissional ou social, bem como, compartilhar tais informações e conhecimentos aos demais membros pertencentes a sua comunidade.

A partir desse contexto, os processos de aprendizagem "são múltiplos, contínuos, híbridos, formais e informais, organizados e abertos, intencionais e não intencionais" (MORAN, 2018, p.3). Com base nessas reflexões e, a partir das formas de construir a estrutura metodológica e curricular dos cursos e disciplinas, pode-se validar a metodologia do ensino híbrido, pois ela possibilita dosar a formação (competências cognitivas e socioemocionais) e sobrepujar as barreiras em saber conviver e aprender juntos (CALDEIRA; BRITO, 2019).

Entretanto, não se pode descartar o modelo tradicional de ensino (inovação sustentada), aplicando tão somente os novos modelos (inovações disruptivas), pois o ensino tradicional é um espaço significativo, tanto pelo mérito institucional, quanto pelas certificações e investimentos envolvidos (MORAN, 2018). É necessário o consenso e equilíbrio das ações para que seja aproveitado o que de melhor cada método pode proporcionar na transmissão do conhecimento.

Apoiando-se na inovação disruptiva, com base no emprego do hibridismo na sala de aula, pode-se proporcionar 
a oportunidade de dar a "voz" ao discente, pois a partir das tecnologias, gera-se a personalização da aprendizagem que oportunizará à ele, em seu ritmo, formular seu entendimento de acordo com as informações e conhecimentos transmitidos (NANTES, 2019).

De acordo com as pesquisas de Velasques et al. (2020), fora identificado que há uma triangulação interativa entre docentes, discentes e os conteúdos disponibilizados e ministrados, onde, tais materiais podem sofrer alterações em decorrência da utilização e aplicação das tecnologias, proporcionando a partir das tecnologias, novas relações entre estes sujeitos.

Cabe então ao professor recorrer a tecnologia mais adequada para atender suas propostas expressas em seu plano de ensino, objetivando a edificação e lapidação do conhecimento pelo discente e, este por sua vez, irá ampararse a partir dos recursos tecnológicos para interagir com seus grupos de estudos ou mesmo para suas pesquisas individuais em busca da ampliação de suas competências e habilidades requeridas pelo conteúdo analisado. Por fim, o docente necessita agir como um mediador nas propostas elencadas, para que os discentes possam ter a percepção e compreensão necessárias quanto aos conteúdos vislumbrados (VELASQUES et al., 2020).

A partir dos desafios encontrados nos processos de ensino e aprendizagem, se faz necessário apresentar "novas propostas educativas que superem a instrução ditada pelo livro didático, centrada no dizer do professor e na passividade do aluno" (VALENTE; ALMEIDA; GERALDINI, 2017, p. 458).

Diante desse contexto, revisitamos os autores que analisam e discorrem sobre a metodologia do ensino híbrido para amparar-se e validar nosso objeto de pesquisa, tendo como propósito, através do método estatístico qui-quadrado, apresentar quais as características e percepções assimiladas pelos egressos dos cursos do PRONATEC para realizarem ou não a indicação dos cursos ao seu rol de contatos sociais, avaliando os indicadores de qualidade que compuseram os materiais disponibilizados, e assim responder a nossa pergunta norteadora: Será que a qualidade das disciplinas semipresenciais pode influenciar os alunos egressos do PRONATEC a indicarem ou não os cursos ao seu rol de contatos sociais?

\section{Material e Métodos}

Para atendermos o objetivo desta pesquisa, os caminhos metodológicos utilizados para a elaboração deste envolveram um método descritivo, com natureza quanti-qualitativa, tendo como procedimentos técnicos a análise bibliográfica, documental e, a partir da elaboração e aplicação de um questionário estruturado, com 19 perguntas, o levantamento das percepções dos alunos egressos dos cursos do PRONATEC ofertados em uma universidade privada localizada na região norte do Estado Paraná. Tais questionamentos que embasaram a construção desta pesquisa avaliaram: a) a qualidade e acessibilidade de navegação no AVA da IES onde estavam depositados os materiais das disciplinas semipresenciais; b) a qualidade das videoaulas e conteúdo web disponibilizados em cada disciplina; c) a mediação dos tutores nos fóruns de interação e debate de acordo com os temas propostos pelos professores; d) a avaliação no contexto geral da disciplina ofertada no AVA e; e) se o mesmo indicaria ou não os cursos ofertados pelo programa às suas redes sociais, após a conclusão.

Para validar o resultado obtido quanto ao grau de satisfação dos egressos e a indicação ou não dos cursos às suas redes de contato pessoal, o método estatístico escolhido para nortear essa pesquisa foi o qui-quadrado, pois de acordo com Martins e Domingues (2017, p. 208), “os testes paramétricos são particularmente úteis para decisões sobre dados oriundos de pesquisas da área de ciências humanas". A característica principal do teste qui-quadrado é que ele pode ser utilizado para realizar testes de adequação ou de aderência, onde seu grau de significância deve ser inferior a $5 \%(\mathrm{p}<0,05)$.

Para ancorar a caracterização dos dados, recorreu-se à Análise de Conteúdos, conforme proposto por Bardin (2011). De forma sintetizada e, de acordo com o pesquisador, a análise de conteúdo pode a análise dos significados (exemplo: a análise temática), embora possa ser também a análise dos significantes (análise lexical, análise dos procedimentos). Tais asserções possibilitaram agrupar as enunciações dos participantes por traços de similaridade.

Como limitações desta pesquisa, observa-se o grande número de questionários eletrônicos sem a devolutiva dos alunos. Após a sistematização dos dados, apurou-se os seguintes resultados:

Figura 1 - Aplicação de questionários

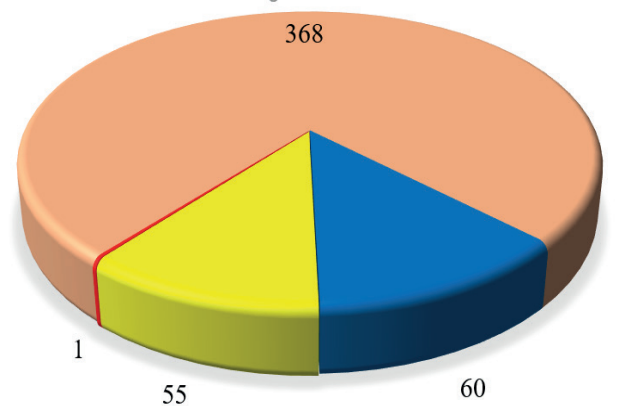

$\square$ Sem devolutiva $\mathbf{Q}$ Q. Respondidos 4 E-mail errado $\mathbf{a}$ Não Respondeu Fonte: Dados da pesquisa.

Dentre os 484 alunos pesquisados, apurou-se que 60 alunos $(12,40 \%)$ responderam o questionário, um aluno $(0,21 \%)$ negou-se em participar da pesquisa. Enfatiza-se que o questionário eletrônico, no período aplicado, foi enviado duas vezes a todos os alunos formandos elencados para esta pesquisa, utilizando-se do endereço com domínio GMAIL e com o domínio corporativo. As limitações encontradas para a aplicação do questionário foram os endereços eletrônicos registrados no sistema de forma errônea $(11,36 \%)$ e a falta de retorno dos alunos (76,03\%), sem uma justificativa. De acordo com Malhotra (2006), as hipóteses prováveis para as 
respostas que não ocorreram seriam:

a) O desinteresse dos alunos em participarem da pesquisa;

b) Os e-mails enviados terem sido direcionados diretamente para a caixa de spam;

c) A falta de tempo para poder responder os questionários;

d) Falta de habilidade dos respondentes.

Mesmo diante das hipóteses levantadas, as quais poderiam gerar a negativa das respostas, a escolha da aplicação de um questionário eletrônico foi motivada por ser a internet um facilitador na comunicação entre muitos, em uma escala global e no tempo escolhido pelos participantes para responder o documento (CASTELLS, 2004). Na IES escolhida para acesso à informação dos alunos egressos e aplicação dos questionários eletrônico, não houve nenhuma dificuldade em se obter tais dados, pois, os diretores das unidades pesquisadas apoiaram o projeto e forneceram total colaboração.

\section{Resultados e Discussão}

De acordo com os dados obtidos, apurou-se que 41 alunos $(68,33 \%)$ afirmaram que o acesso e a navegação eram fáceis e o tutorial bem elaborado e explicativo, sendo compreensível o que se pedia nas atividades a serem realizadas; 13 alunos $(21,67 \%)$ alegaram que a navegação era muito complexa, não compreendendo o que era para ser realizado e os prazos para executar as atividades e; seis alunos (10\%) afirmaram que o layout do AVA era desorganizado, gerando dúvidas quanto a sequência das atividades a serem realizadas, conforme demonstrado no gráfico da Figura 2.

Figura 2 - Avaliação da navegação no AVA

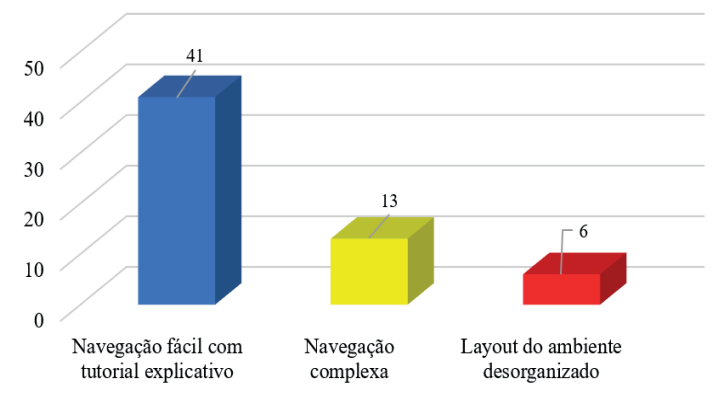

Fonte: Dados da pesquisa.

Tais resultados apurados geram uma reflexão quanto ao letramento digital e a forma como os alunos absorveram o conhecimento necessário para interagir com um ambiente virtual.

Antes do domínio digital, é fundamental se ter o domínio da escrita e leitura para que se possa ter maior compreensão do que é solicitado durante o desenvolvimento de uma atividade.

Para Kenski (2012), o AVA deve garantir funcionalidades e navegabilidade, auxiliando o aprendizado do aluno. Além disso, o suporte dos tutores, professores ou instrutores deve ocorrer ativamente, para que o aluno não se sinta abandonado e prejudicado na execução de suas atividades (MOORE; KEARSLEY, 2013).

Os resultados acurados junto aos participantes da pesquisa quanto à qualidade das Webaulas (material de apoio) disponibilizadas no AVA, pertinente às disciplinas semipresenciais, do quais os alunos efetuavam a leitura para terem conhecimento sobre o assunto ministrado, 51 alunos $(85 \%)$ informaram que estes eram de fácil compreensão e estavam coerentes com o cenário atual, enquanto nove alunos (15\%) relataram ser os materiais complexos e desatualizados, sendo difícil a compreensão das propostas apresentadas na webaula.

Os materiais de apoio para a compreensão dos alunos são de suma importância, pois neles o professor criará um diálogo com os alunos, ilustrando exemplos, apresentando teoria dos autores que corroboram com o assunto e indicar links de artigos e vídeos que enaltecerão o conhecimento e aprendizagem do aluno (GOMES, 2007). Este material de apoio fornecerá informações úteis relacionadas à temática da aula, auxiliando na resolução das atividades propostas pelo professor (KENSKI, 2012).

No gráfico da Figura 3, é apresentado a percepção dos alunos quanto às videoaulas disponibilizadas no AVA.

Figura 3 - Avaliação sobre as videoaulas

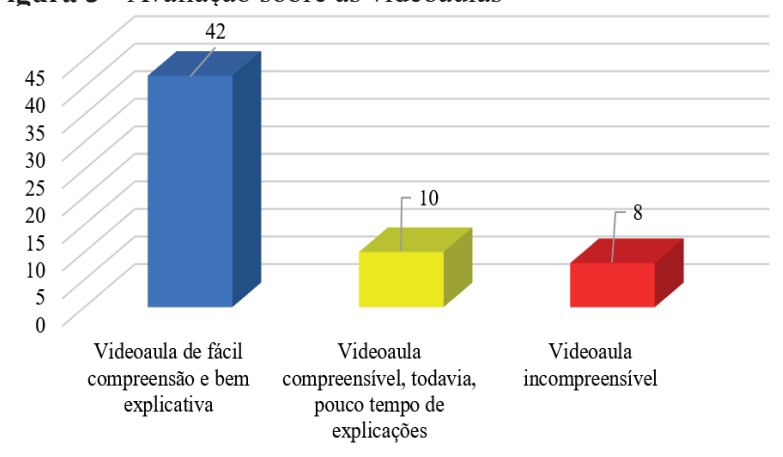

Fonte: Dados da pesquisa.

Após a coleta dos dados, observou-se que 42 alunos (70\%) responderam que as videoaulas são de fácil compreensão e bem explicativas, complementando o conteúdo disponibilizado nas webaulas; 10 alunos $(16,67 \%)$ informaram que as videoaulas eram compreensíveis, porém, o tempo disponibilizado era muito curto, não possuindo tempo necessário para os professores explicarem e ministrarem o conteúdo proposto e; oito alunos $(13,33 \%)$ citaram que as videoaulas eram incompreensíveis, não auxiliando e esclarecendo o conteúdo absorvido no decorrer da leitura.

Se faz necessário explicar a diferença entre videoaulas e teleaulas. Segundo Machado e Moraes (2015), a primeira é uma aula gravada pelo professor, de forma assíncrona e fica disponibilizada pelo aluno no AVA; já a segunda modalidade ocorre ao vivo, com a aula transmitida via satélite ou por um canal exclusivo, sendo depositada posteriormente no AVA.

A vantagem da teleaula é que o aluno pode esclarecer suas dúvidas de forma síncrona, ou seja, no mesmo instante em que a aula ocorre, já na videoaula, caso surja alguma dúvida durante a realização do seu estudo, o mesmo deverá entrar em contato com o seu tutor para sanar suas dúvidas e aguardar o 
retorno do mesmo.

Outro ponto analisado no escopo das disciplinas semipresenciais compreende a utilização e mediação dos fóruns existentes, nos quais os alunos e tutores abordavam temas propostos pelos professores que complementavam os conteúdos ministrados.

É possível observar no gráfico da Figura 4 como os alunos avaliaram a aplicabilidade dos fóruns.

Figura 4 - Avaliação dos fóruns

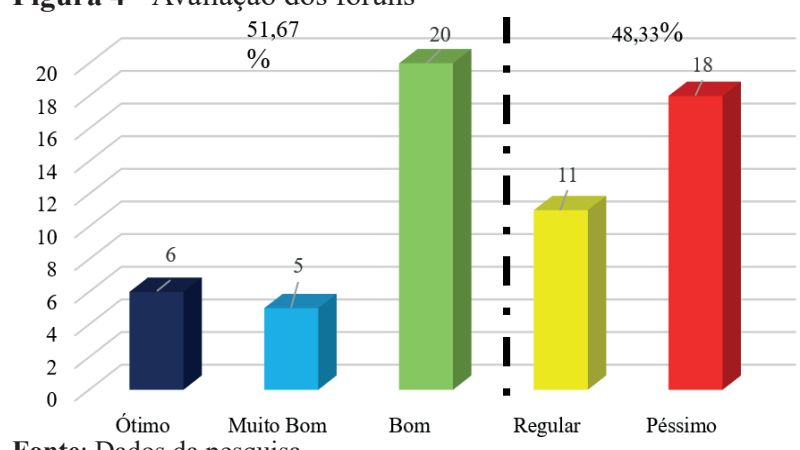

Fonte: Dados da pesquisa.

De acordo com os dados apurados, 51,67\% dos alunos conceituaram os fóruns entre ótimo, muito bom e bom e, os outros $48,33 \%$ dos alunos atribuíram conceitos entre regular e péssimo. A avaliação predominante entre os alunos foi o conceito bom, o qual obteve 20 notas $(33,33 \%)$; o conceito regular obteve 11 notas $(18,33 \%)$ e o conceito péssimo obteve 18 notas $(30,00 \%)$. O conceito ótimo obteve seis notas (10\%) e o conceito muito bom obteve cinco notas $(8,33 \%)$. Tais resultados remetem a uma reflexão quanto à forma de mediação e utilização dos espaços que os fóruns criaram para os alunos interagirem entre si e os tutores.

Para Lakatos e Marconi (1999, p. 87), a mediação e interação deve ocorrer nos fóruns como:

[...] interação social é ação social, mutuamente orientada, de dois ou mais indivíduos em contato. Distingue-se da mera interestimulação em virtude de envolver significados e expectativas em relação às ações de outras pessoas. Podemos dizer que a interação é a reciprocidade de ações sociais.

O propósito dos fóruns é exatamente criar uma interatividade entre os membros que participam daquele grupo de estudos. O papel do tutor ou professor, é tornar este ambiente propício para um debate saudável sobre todos os conteúdos elencados como importantes, para ampliar a reflexão sobre os temas analisados.

Deve ser lembrado que o papel dos tutores e professores são diferentes no modelo de ensino a distância. O professor é responsável pela elaboração dos conteúdos que serão ministrados, produzir os materiais didáticos, como livros e webaulas, confeccionar as provas e efetuar as proposições dos temas que serão debatidos nos fóruns. Já o tutor, tem o seu papel como mediador entre professores, alunos e conteúdo, facilitando o processo de ensino e aprendizagem e, orientar os alunos por meio eletrônico (MORAN, 2013; KENSKI, 2015).

Para Machado e Moraes (2015), os fóruns são um ambiente de interação entre professores, tutores e alunos, nos quais discussões são promovidas, circundando um tema que está sendo analisado na disciplina ministrada. Contudo, ter os recursos tecnológicos e um AVA sofisticado, não gerará resultados positivos caso não ocorra um diálogo entre as partes envolvidas. Afirma Bakthin (1992, p. 334) que "[...] a dialogia ocorre quando a interação entre os sujeitos favorece a constituição mútua de ambos, em devir, numa relação horizontal, que refuta a diretividade unilateral".

Diante do contexto, afirma Silva (2006, p.11) que

na modalidade comunicacional permitida pelas novas tecnologias informáticas, há uma mudança significativa na natureza da mensagem, no papel do emissor e no estatuto do receptor. A mensagem torna-se modificável na medida em que responde às solicitações daquele que a consulta, que a explora, que a manipula.

Tal proposição realizada por Silva (2006) identifica-se com o resultado obtido por intermédio dos dados coletados perante os alunos pesquisados, uma vez que houve uma variação muito grande nos conceitos que eles atribuíram para os fóruns realizados, onde cada aluno recebeu e interpretou as discussões de determinada forma, gerando vários estilos de comentários e sugestões.

Para Moore e Kearsley (2013), cabe ao tutor identificar as diferenças dos alunos e lidar com elas, sendo um ator motivacional e incentivador neste processo de aprendizagem.

Dando continuidade à análise, fora solicitado aos alunos que avaliassem a mediação dos tutores no transcorrer das atividades do curso, sendo obtido os seguintes resultados apontados na Figura 5

Figura 5 - Avaliação sobre a mediação dos tutores

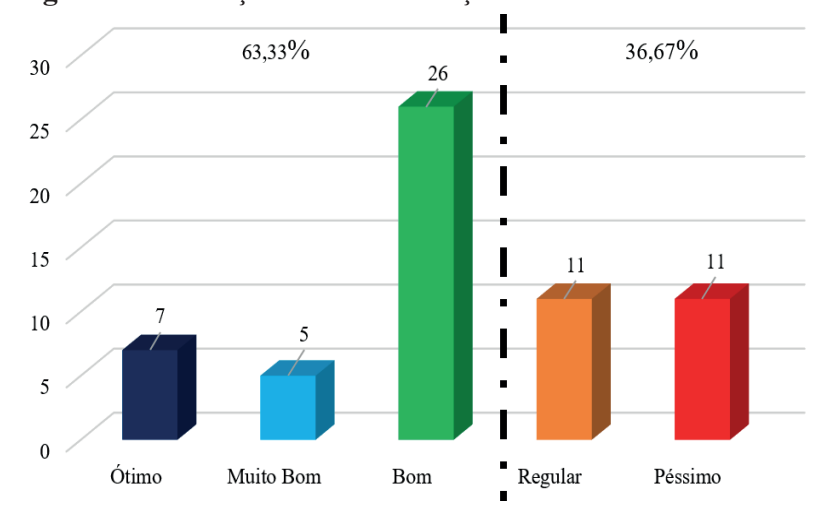

Fonte: Dados da pesquisa.

Após a sistematização dos dados e apuração das informações, o conceito bom obteve 26 notas (43,33\%); ambos conceitos, regular e péssimo, obtiveram, cada um, 11 notas, correspondendo a $36,67 \%$ e os conceitos, ótimo e muito bom obtiveram 12 notas, correspondendo a $20 \%$.

De acordo com Veiga (2006, p. 13), “o processo didático tem por objetivo dar respostas a uma necessidade: ensinar. $\mathrm{O}$ resultado de ensinar é dar respostas a uma outra necessidade: a do aluno que procura aprender". Logo, recai sobre os 
mediadores (professores e tutores) o ônus de um ambiente em que o aluno possa aprender e aplicar os recursos disponíveis, bem como, envolver com o assunto proposto e compreendêlo (MOORE; KEARSLEY, 2013), pois o aluno irá aprender, também, a partir das orientações de pessoas (professores e tutores) mais experientes em diferentes campos e atividades (MORAN, 2018).

Segundo os estudos de Kenski (2012), o relacionamento entre tutores e alunos poder ser alterado pelo uso das tecnologias, principalmente se estas forem utilizadas intensamente.

É necessário enfatizar que professores e tutores necessitam respeitar os diferentes ritmos de aprendizagem dos alunos, pois nem todos aprendem do mesmo modo e ao mesmo tempo (MORAN, 2018).

Sobre essa temática, Dias (2008, p.4-10) apresenta que

o principal papel do e-moderador consiste em promover o envolvimento dos participantes de modo que o conhecimento por eles construído seja utilizável em novas e diferentes situações. Promover um processo de construção e significados, e não de transmissão de conteúdo [...] com efeito, a experiência educacional emerge da combinação entre adequada organização das atividades de aprendizagem, contexto e estilo de intervenção e o acompanhamento do moderador [...] São funções do moderador a organização da comunidade, a disponibilização das sequencias dos conteúdos e a gestão das aprendizagens por meio do incentivo à participação e avaliação dos processos (2008, p. 4-10).

O papel do moderador (professor e tutor), além de responder aos questionamentos enviados pelos alunos, é incentivar e cativar a participação de todos, objetivando a construção ou reconstrução do que fora proposto na atividade.

O debate saudável irá auxiliar os alunos no processo de aprendizagem e compreensão do conteúdo ministrado. $\mathrm{O}$ aluno não deve ter somente a percepção de obrigatoriedade de participação para receber uma nota ou presença. É relevante tal apontamento, devido ao fato de que, durante a prática da aula e após a análise do gráfico, 26 alunos conceituaram como "bom" este momento de atividade e aprendizagem.

Observa-se que as mediações e interações entre alunos e tutores serão sempre diferenciadas, pois irão depender das dúvidas e sugestões dos alunos no ambiente do fórum.

Cabe, então, o que Moore e Kearsley (2013, p. 186-189) nos apresenta:

Finalmente, os instrutores dão conselhos, apoio e encorajamento a cada aluno, aprimorando o conhecimento pessoal que tem com seus alunos, conhecimento que não é acidental, mas adquirido deliberadamente por cada instrutor no início de cada curso como um requisito fundamental de seu papel como instrutor. [...] Além de proporcionar intercâmbio de informações e incentivar a interação aluno-aluno e instrutor-aluno, o instrutor oferece estruturas permanentes do curso, cuja finalidade é promover o contato social entre alunos e instrutor.

A humanização na participação dos fóruns se faz necessária para suprir a ausência física e criar um ambiente agradável para estudos e proposições. A dialogia, proposta por
Bakthin (1992), é o grande segredo para que todos os alunos possam ver com bons olhos a importância da participação nos fóruns e, ao tutor, cabe a responsabilidade da empatia e conhecimento do assunto para não desestimular o aluno enquanto este estiver desenvolvendo o seu aprendizado.

Após todos estes questionamentos quanto à percepção da qualidade dos materiais, atividades e mediação empregada nas disciplinas semipresenciais, efetuou-se um cruzamento de todas as enunciações desses participantes para saber quais fatores poderiam influenciar na indicação ou não dos cursos do PRONATEC, sendo este o objeto da pesquisa realizada.

Aplicando o método estatístico qui-quadrado e efetuando os cálculos sobre um valor de significância, ou seja, o valor-p 0,05 , obteve-se os seguintes resultados:

a)Os dados amostrais que não indicaram evidências estatísticas, nas quais os conceitos atribuídos pelos alunos não estão associados à indicação ou não dos cursos do PRONATEC foram: navegabilidade no AVA, sendo seu valor-p 0,07, ou seja, maior que o valor de significância; utilização dos fóruns, sendo seu valor-p 0,34, ou seja, maior que o valor de significância; disciplinas semipresenciais, sendo seu valor-p 0,93 , ou seja, maior que o valor de significância;

b) Os dados amostrais que indicaram evidências estatísticas, nas quais os conceitos atribuídos pelos alunos estão associados à indicação ou não dos cursos do PRONATEC foram: webaula, sendo seu valor-p 0,0029, ou seja, menor que o valor de significância; vídeoaulas, sendo seu valor-p 0,0002, ou seja, menor que o valor de significância e; mediação dos tutores, sendo seu valor-p 0,027 , ou seja, menor que o valor de significância.

Mesmo obtendo-se alguns resultados negativos, os discentes egressos entrevistados ficaram satisfeitos com a forma que foram trabalhadas as disciplinas semipresenciais, tanto em sua estrutura, quanto aos materiais disponibilizados no AVA.

De acordo com os resultados obtidos, 32 alunos, ou seja, $53,33 \%$ consideraram as disciplinas semipresenciais como ótimas, muito boas ou boas na atribuição de conceitos e, 28 alunos, ou seja, 46,67\% atribuíram conceitos regular ou péssimo. Observa-se que os conceitos positivos e aceitação às disciplinas, foi maior do que a repulsa por parte dos alunos.

A avaliação geral dos alunos quanto às disciplinas semipresenciais fora constituída conforme gráfico da Figura 6.

Figura 6 - Avaliação Geral das Disciplinas Semipresenciais

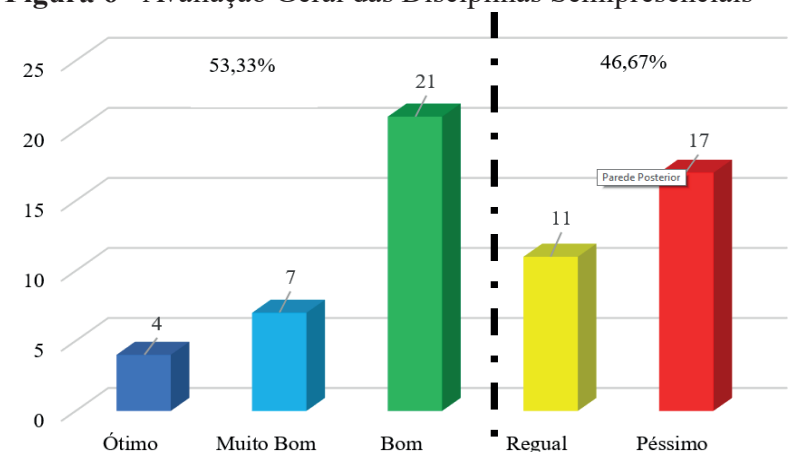

Fonte: Dados da pesquisa. 
Como observou-se na apresentação das informações, houve uma grande proximidade entre os conceitos "positivos" e "negativos", o que possibilitou uma reflexão sobre a forma como a instituição atribuiu os conteúdos interativos em sua matriz curricular do PRONATEC. Assim, por meio dos resultados obtidos, referentes à utilização e aplicação dos conteúdos semipresenciais, pode-se analisar que muitos alunos, quando criticaram ou apontaram defeitos para as disciplinas semipresenciais, apresentaram em suas justificativas que inscreveram-se para estudar presencialmente os cursos do PRONATEC e não a distância.

\section{Conclusão}

Nesta pesquisa buscou-se apresentar a perspectiva dos alunos egressos do PRONATEC quanto à qualidade das disciplinas semipresenciais ofertadas em seus respectivos cursos, fazendo uma análise quanto à navegabilidade no AVA, os conteúdos disponibilizados nas webaulas e videoaulas, bem como a atuação dos tutores efetuando a mediação no processo de ensino-aprendizagem e, a partir destes dados, apresentar estatisticamente quais elementos poderiam influenciar ou não na indicação dos cursos para a rede de contatos que os egressos possuíam.

Como resultado final, os dados amostrais extraídos das informações prestadas pelos egressos e a apuração do teste estatístico qui-quadrado, demostraram que os tópicos de maior motivação para a indicação ou não dos cursos do PRONATEC foram os conteúdos disponibilizados nas webaulas, às videoaulas e a mediação realizada pelos tutores do PRONATEC. Mediante este resultado, verificou-se que as availiações atribuídas pelos egressos a estes elementos foram determinantes e significantes para influenciar na indicação ou não dos cursos do PRONATEC, onde, 52 alunos (86,66\%) afirmaram que indicariam os cursos para sua rede de contatos.

Assim, é necessário saber explorar todas as possibilidades para tornar os conteúdos interativos e atrativos, despertando a curiosidade naqueles que utilizam os meios tecnológicos, para que as disciplinas semipresenciais não se tornem somente mais uma disciplina, ou venha gerar um desconforto para o discente em decorrência da qualidade dos materiais disponibilizados no AVA, e proporcionar a disponibilização de uma plataforma que seja de fácil interação e navegabilidade.

\section{Referências}

BACICH, L.; TANZI NETO, A.; TREVISANI, F.M. Ensino híbrido: personalização e tecnologia. In: BACICH, L. Ensino híbrido: personalização e tecnologia. Porto Alegre: Penso, 2015. p.43-57.

BACKES, L.; CHITOLINA, R.F.; BARCHINSKI, K.C. A configuração do hibridismo na educação on-line: desafios para a prática pedagógica. In: SEMINÁRIO INTERNACIONAL PESSOA ADULTA, SAÚDE E EDUCAÇÃO. 2017. Disponível em $<$ https://editora.pucrs.br/acessolivre/anais/sipase/assets/ edicoes/2018/arquivos/33.pdf $>$. Acesso em: 2 mar.2020.

BAKTHIN, M.M. Estética da criação verbal. São Paulo: Martins
Fontes, 1992.

BARDIN, L. Análise de conteúdo. São Paulo: Edições 70, 2011.

BASSO, C. Aspectos pessoais e contextuais favoráveis à permanência de estudantes em cursos técnicos do PRONATEC. 2014. 196 f. Tese (Doutorado em Psicologia) - Universidade Federal de Santa Catarina, Florianópolis, 2014.

BORGES, L.M.; LOPES, R.P. O conceito de Blended Learning: breve revisão teórica. In: MONTEIRO, S.A.S. Formação docente: princípios e fundamentos. Ponta Grossa: Atena, 2019. p.9-17.

BRASIL. Minstério da Educação. Portaria MEC n ${ }^{\circ} 4.059$, de 10 de dezembro de 2004. Disponível em: <http://portal.mec.gov.br/ sesu/arquivos/pdf/nova/acs_portaria4059.pdf $>$. Acesso em: 15 mar. 2020.

BRASIL. Minstério da Educação. Portaria MEC n 2.117, de 6 de dezembro de 2019. Disponível em: $<$ http://www.in.gov.br/en/web/ dou/-/portaria-n-2.117-de-6-de-dezembro-de-2019-232670913>. Acesso em: 30 jan. 2020.

CALDEIRA, E.; BRITO, G.L.R. O uso de tecnologias educacionais e metodologias ativas em práticas de letramentos no ensino superior: produção de artigo e revisão de literatura. In: MONTEIRO, S.A.S. Formação docente: princípios e fundamentos. Ponta Grossa: Atena, 2019. p.143-154.

CASTELLS, M. Comunidades virtuais ou sociedade em rede? In: CASTELLS, M. A galáxia da internet: reflexões sobre internet, negócios e sociedade. Rio de Janeiro: Jorge Zahar, 2004. p.145-166.

DIAS, P. Da e-moderação à mediação colaborativa nas comunidades de aprendizagem. Educ. Formação Tecnol., v.1, n.1, p.4-10, 2008.

FARIAS, H.P.S. et al. O ensino híbrido como estratégia de ensino na educação superior. In: FERREIRA, G.R. Educação e tecnologias: experiências, desafios e perspectivas. Ponta Grossa: Atena, 2019, p.119-132.

GOMES, T.S.L. Desenvolvimento de ambientes virtuais: novos desafios. In: CORRÊA, J. (Org.). Educação a distância: orientações metodológicas. Porto Alegre: Artmed, 2007. p.47-66.

HORN, M.B.; STAKER, H. Blended: usando a inovação disruptiva para aprimorar a educação. Porto Alegre: Penso, 2015.

KENSKI, V.M. Educação e tecnologias: o novo ritmo da informação. Campinas: Papirus, 2012.

KENSKI, V.M. Tecnologias e ensino presencial e a distância. Campinas: Papirus, 2015.

LAKATOS, E.M.; MARCONI, M.A. Sociologia geral. São Paulo: Atlas, 1999.

MACHADO, D.P.; MORAES, M.G.S. Educação a distância: fundamentos, tecnologias, estrutura e processo de ensino e aprendizagem. São Paulo: Érica, 2015.

MALHOTRA, N. Pesquisa de marketing: uma orientação aplicada. Porto Alegre: Bookman, 2006.

MARTINS, G.A.; DOMINGUES, O. Estatística geral e aplicada. São Paulo: Atlas, 2017.

MASSETO, M.T. Mediação pedagógica e tecnologias de informação e comunicação. In: MORAN, J.; MASSETO, M.T.; BEHRENS, M.A. Novas tecnologias e mediação pedagógica. Campinas: Papirus, 2013. p.141-171.

MILL, D. Dicionário crítico de educação e tecnologias e de educação a distância. Campinas: Papirus, 2018. 
MOORE, M.G.; KEARSLEY, G. Educação a distância: sistemas de aprendizagem on-line. São Paulo: Cengage Learning, 2013.

MORAN, J. A educação que desejamos: novos desafios e como chegar lá. Campinas: Papirus, 2013.

MORAN, J. Educação híbrida: um conceito-chave para a educação, hoje. In: BACICH, L.; TANZI NETO, A.; TREVISANI, F.M. Ensino híbrido: personalização e tecnologia na educação. Porto Alegre: Penso, 2015.

MORAN, J. Metodologias ativas para uma aprendizagem mais profunda. In: BACICH, L.; MORAN, J. Metodologias ativas para uma educação inovadora: uma abordagem teórica-prática. Porto Alegre: Penso, 2018.

NANTES, E.A.S. Relato de experiência sobre a implantação do ensino híbrido em uma disciplina do stricto sensu. 2019. Monografia (Especialização em Inovação e Tecnologias na Educação) - Universidade Tecnológica Federal do Paraná, Curitiba, 2019.
OLIVEIRA, S. Modos de ser estudante e as pedagogias ativas: autonomia e aprendizagem na experiência do indivíduo livre. In: BLASIUS, D. Metodologias ativas no ensino superior: o protagonismo do aluno. Porto Alegre: Penso, 2020. p.9-20.

SILVA, M. Sala de aula interativa. Rio de Janeiro: Quartet, 2006.

VALENTE, J.A.; ALMEIDA, M.E.B.; GERALDINI, A.F.S. Metodologias ativas: das concepções às práticas em distintos níveis de ensino. Rev. Diálogo Educ., v.17, n. 52, p.455-478, 2017. doi: http://dx.doi.org/10.7213/1981-416X.17.052.DS07

VEIGA, I.P.A. (Org.). Lições de didática. Campinas: Papirus, 2006.

VELASQUES, F.V. et al. Ensino híbrido aplicado: relatório de experiência com estudantes de pós-graduação. Rev. Educ. Ciênc. Tecnol., v.9, n.1, 2020. doi: 10.35819/tear.v9.n1.a3967

VYGOTSKY, L.S. A formação social da mente. São Paulo: Martins Fontes, 1991. 